\title{
MEMÓRIA DO GESTO
}

\section{GESTURE OF MEMORY}

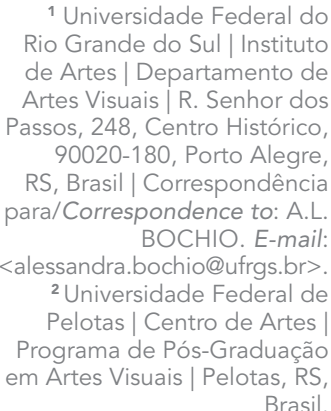

Como citar este artigo How to cite this article BOCHIO, A. L.; CASTELLANI

F. M. Memória do gesto. Pós-Limiar, v. 3, e204966 2020 https://doi.org/10.24220/2595-9 $557 v 3 e 2020 a 4966$

Recebido em 22/5/2020 e aprovado em 25/8/2020

\author{
Alessandra Lucia Bochio1 \\ ORCID iD: 0000-0002-3558-9631 \\ Felipe Merker Castellani² \\ ORCID iD: 0000-0002-8532-7365
}

As imagens apresentadas neste ensaio visual são decorrentes de uma série de vídeos, que foram construídos a partir de pequenos gestos, criados para estar em performance. Aqui ganham outra versão, ou melhor, outra atualização. Trata-se de híbridos, que estão entre a fixidez das imagens e a produção de presença das performances. São imagens que, ao mesmo tempo em que são atravessadas pela gestualidade e pela taticidade, são traços ou rastros de um amplo processo de diálogo das nossas pesquisas artísticas, que se cristalizam agora em formas fixas. Evocam, ao menos para nós, a memória - como suspensão do mundo. A memória do corpo, do gesto, da performance, bem como de processos criativos que ficaram para trás e de pesquisas que tomaram outros rumos, mas que se apresentam aqui por meio de novos questionamentos. De maneira paradoxal, evocam ainda a memória como forma de armazenamento, no caso o armazenamento digital, registrado em sequências de 0 e 1.

Parece-nos oportuno trazer o híbrido performance-imagem neste momento, principalmente a partir de suas próprias contradições. Em tempos de isolamento social, a presença mediada pela imagem digital tem tido uma ênfase constante. Não que não tivesse anteriormente, mas o digital tem se tornado cada vez mais o refúgio em que os indivíduos constroem seus esconderijos das imperfeições do mundo físico e do corpo a corpo das relações intersubjetivas, conforme mencionou recentemente Achille Mbembe.

Reiteramos, não há melhor momento para pensar a produção de presença mediada pela imagem digital, a qual, por meio da sua matriz binária, generaliza a memória dos corpos, dos gestos, das performances, reduzindo-a às supostas universalidades e sequências numéricas.

"Até o outro dia", como argumenta Mbembe, "[...] é na esfera digital que parecida residir o destino dos conjuntos humanos e da produção material, bem como os seres vivos. [...] Bastava transferir o conjunto de aptidões do ser vivo para um duplo digital que estaria tudo resolvido" (MBEMBE, 2020, online). A generalidade do digital seria capaz de apagar todas as contradições e diferenças. Os corpos, os gestos, as performatividades e suas memórias seriam então pasteurizados para eliminar qualquer resíduo estranho. No entanto, argumenta ele, "não importa o quanto tentemos nos livrar disso, tudo remete, por fim, ao corpo". 
Convidamos no ensaio visual Memória do gesto as leitoras e os leitores a percorrerem algumas memórias numéricas de gestos, atos físicos presentificados que buscam tensionar e colocar ruído na assepsia do mundo digital descorporificado que hoje nos engole com seus fluxos imateriais e suas novas formas de vigilância, controle e domesticação social.

\section{REFERÊNCIAS}

MBEMBE, A. O direito universal à respiração. São Paulo: N-1 Edições, 2020. Disponível em: https://www.n-1edicoes.org/textos/53. Acesso em: 15 nov. 2020. 


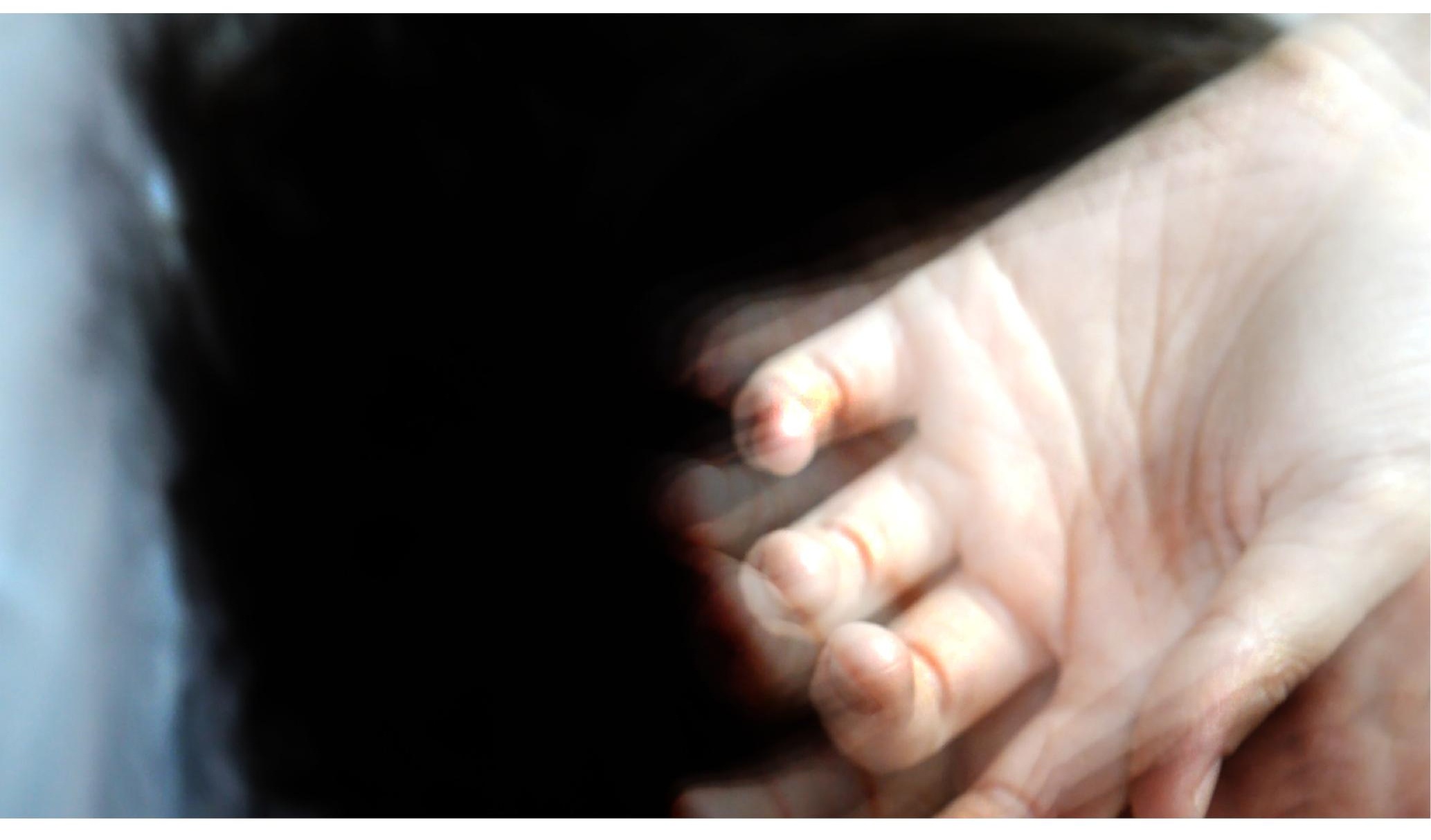




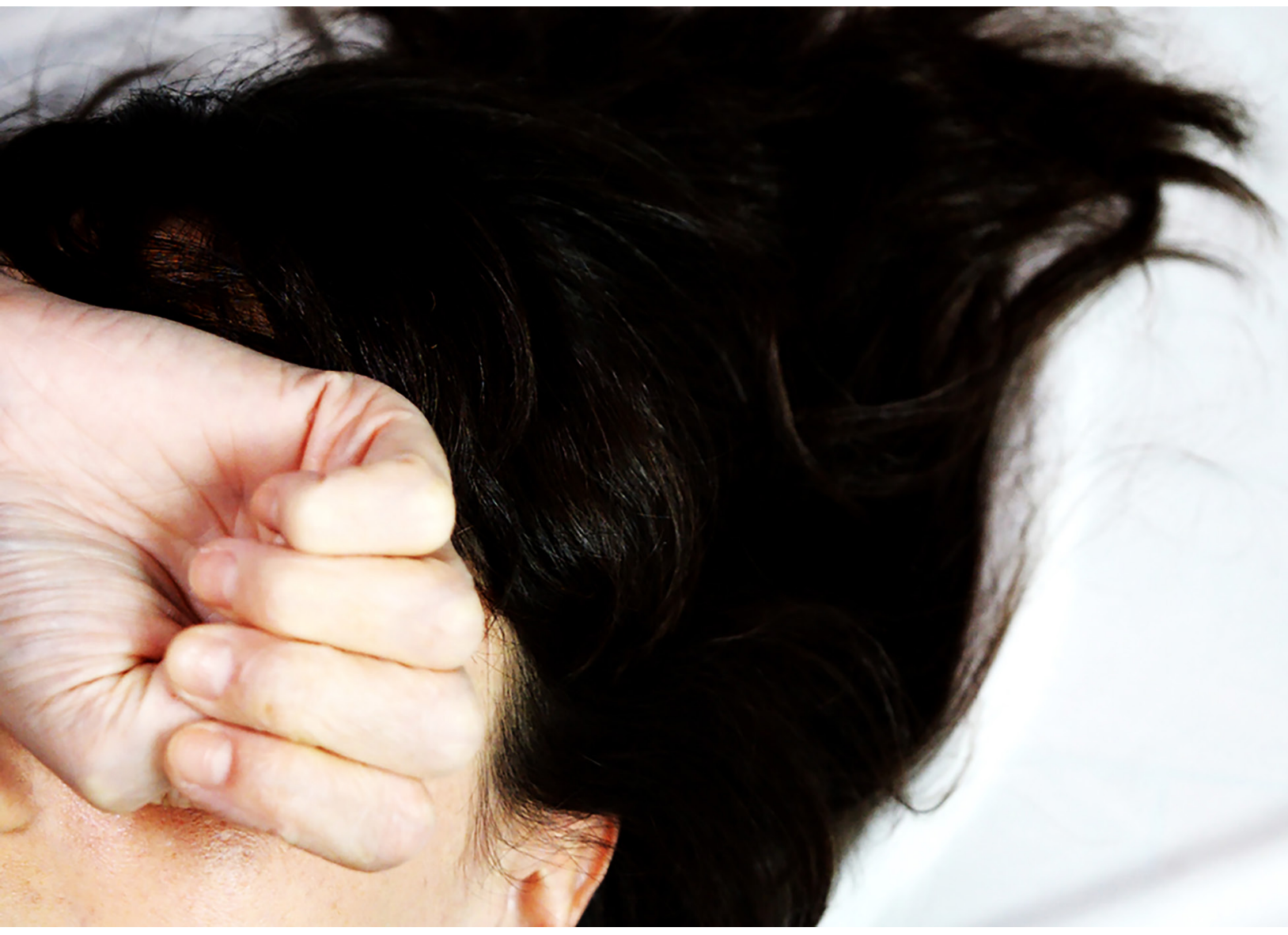




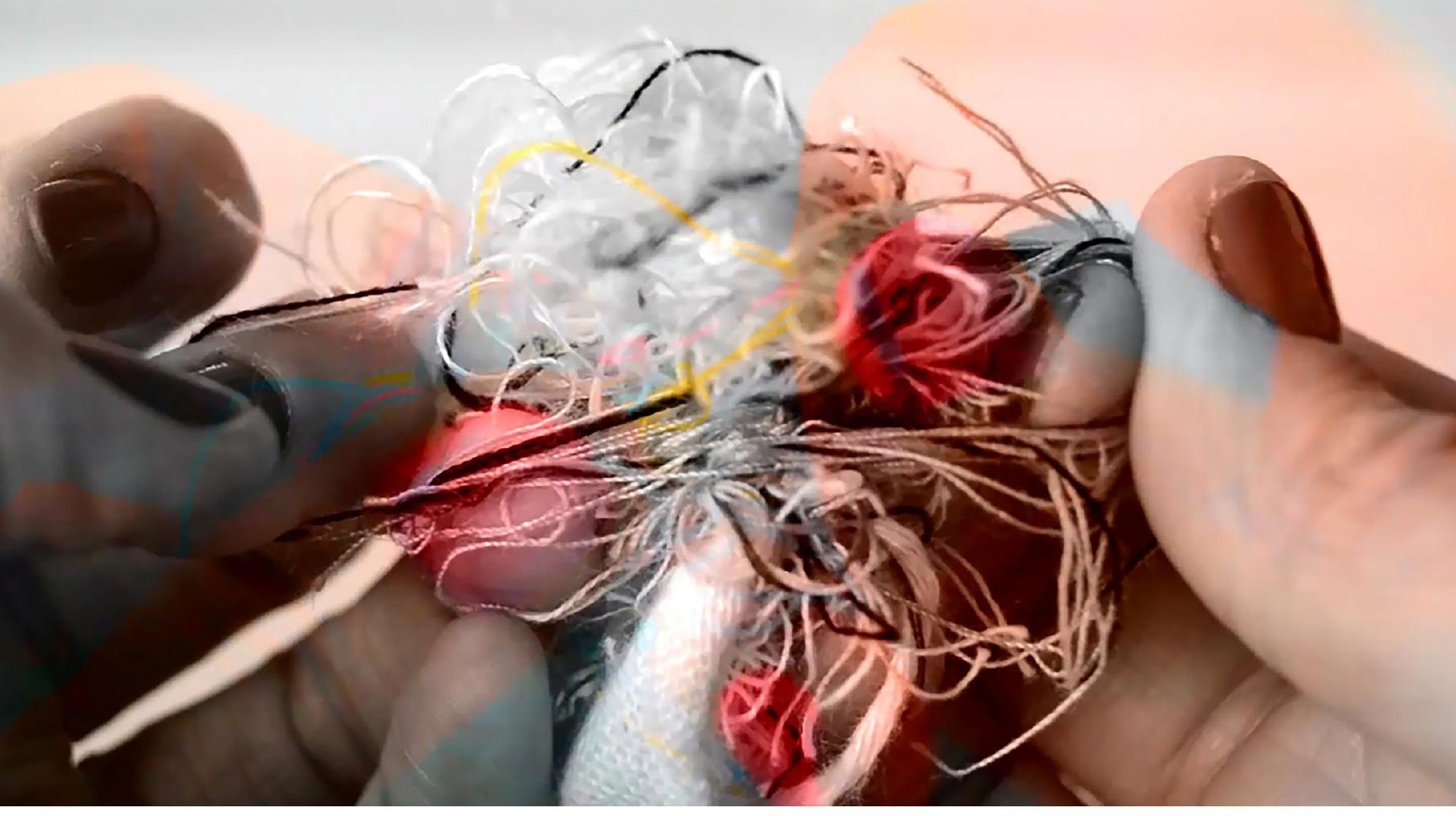




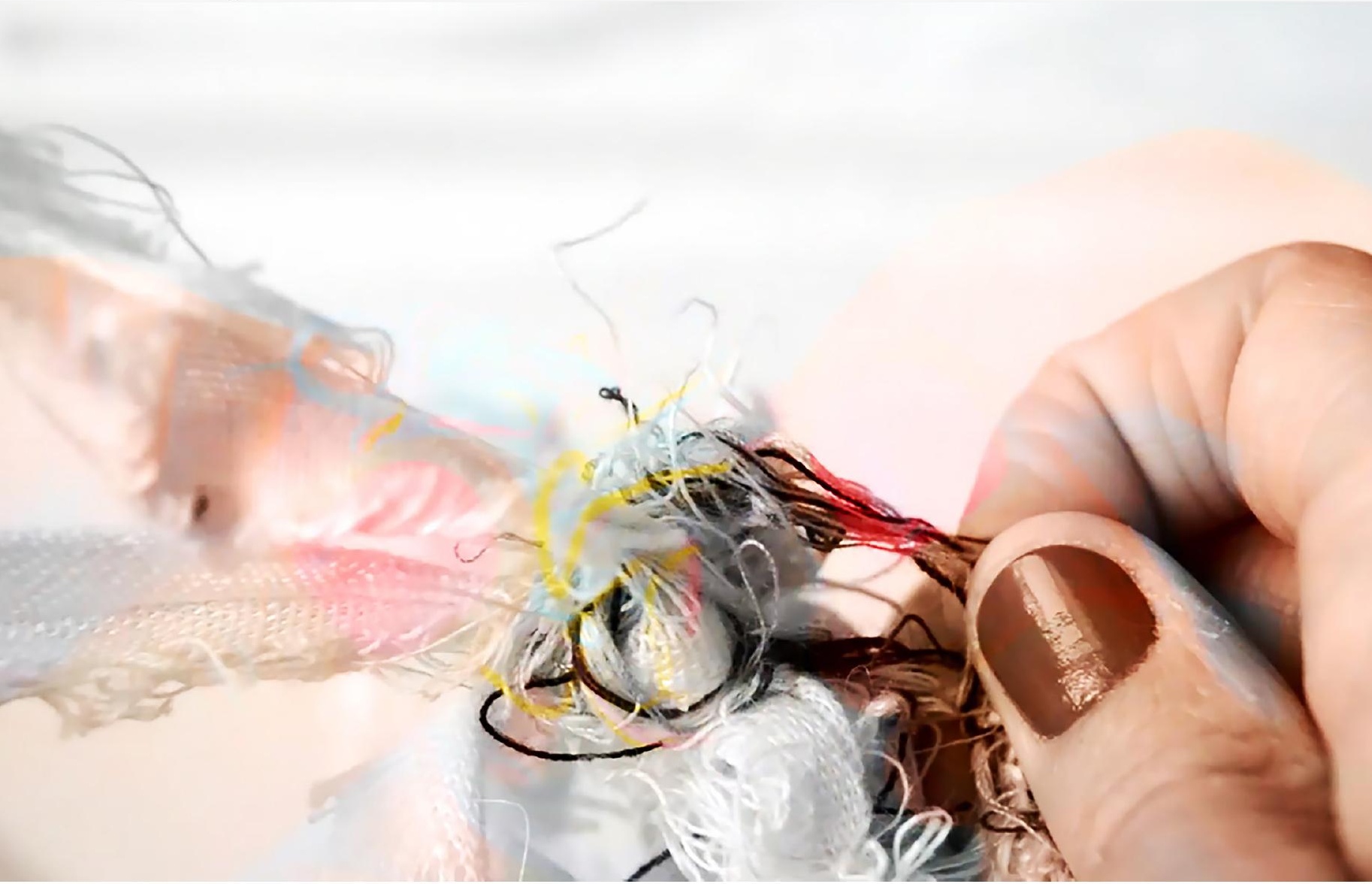

